\title{
Effective Classroom Environment
}

\author{
Swati Tyagi \\ Research Scholar (Education) \\ Career Point University \\ Kota Rajasthan
}

\begin{abstract}
In today's education system behaviour and discipline of students are major concern for all the stakeholders. Most of the teachers have a major concern with regard to myriad of discipline issues that exist in their classes. Classroom environment is a reflection of a teacher as how they make their students comfortable and prepare them for effective learning. It is also vital for student's success not only in academic field but also in social domain. Clear cut expectations, proper feedbacks go a long way but are missing most of the times when educators delve about the topic. Teacher needs to have knack of evaluating children and must even possess ability to do self evaluation. The looming deficit of basic skills prevalent among teachers further widens the chasm. Effective classrooms where sensitivity is practiced bring major change in attitude of students towards school and teaching community. This paper includes the problems and solutions related to the classroom environment and tries to explore unchartered territory and find ways for educators to create soothing environment that would enable teacher and taught to work in conducive environment.
\end{abstract}

Keywords: classroom environment, effective teacher, learning process, student teacher relationship, discipline

\section{Introduction}

Classroom environment includes a vast range of educational concepts, including the physical setting, the psychological environment created through social contexts, and numerous instructional components related to teachers' characteristics and behaviours. Researchers are interested in relationships between environment constructs and multiple outcomes, including learning, engagement, motivation, social relationships, and group dynamics. Scholars who were engaged in research found at early juncture that behaviour is a function of people's personal characteristics and their environment.

Need for Classroom Management: classroom management is necessary to ensure the following-
1. Students have some new take away from each class

2. All learning outcomes for the session are met

3. Developing effective working relationship with students

4. Establishing standards of behaviour that promote student learning

5. Develop a disciplined life style among the students

6. Provide a good social environment

7. Develop thinking, critical and problem solving skills

The onus seems to be on schools that they must provide the best education and cater to the need of every child. For the sake of implementation of their policies, they rely on teachers. In the education field, teachers play a pivotal role for effective classroom management. It is the responsibility of the teachers to make their classes interesting so that students take part in every activity be it academics or co curricular. As mentioned, it is the main responsibility of the teacher to be cautious and responsible for creating positive environment that results in purposeful teaching and the end result is a feeling of trust that surmounts all problems and issues that would have cropped up in the absence of effective classroom environment. So, it can be rightly said that an effective classroom environment is directly correlated with the performance of the students.

Plato rightly opined, "Do not train students to learning by force and harshness but direct them to it by what amuses their mind, so that you may be better able to discover with accuracy the peculiar bent of the genius of each."

Teaching is not dominating but going to the level of the class so that students learn, grow and succeed together. A good relation amongst students and teachers gives a place to the students where they can express their feelings and work together. Academic success depends on a strong, congenial bond, and 
rapport that exists between the teacher and the taught.

Present day researchers focus on a classroom which gives students a safe and secure atmosphere. The physical layouts of a classroom, relationship between teacher and student, psychological environment also have been research subjects recently.

\section{Review of Literature}

Effective teachers develop students learning through interactive instruction which create an effective relationship between teacher and student. An effective teacher creates a good learning environment by using effective teaching techniques and communicating with clarity and accuracy. An effective teacher plays a vital role in student's life. Controlling behaviour of students in classroom is way to enhance learning. At the same time, it is also true that some teacher practices can harm students instead of helping them. Giving physical punishment, sending students out of the class or to the principal's office are some examples.

The review of literature will also be on teaching strategies and ways of reducing disruptive behaviours in the class. The way how a teacher engages his or her students in learning makes a difference in learning environment.

Poulou (2007), views classroom management as an aspect of the teaching profession that teachers encounter in their career and that it ought to be further investigated.

\section{Effective Classroom Environment}

During earlier studies undertaken of classroom atmosphere by erudite scholars, the physical environment has constantly hogged the limelight as it has an impact on behavioral and academic outcomes. Recent studies of the physical environment have examined features such as class composition, class strength, and classroom management.

\section{Physical Layout of Classroom:}

Class composition is a study of inspecting classroom grouping methods, including ability grouping of students and collaborative learning groups. Researches undertaken by eminent educationalists have found that classrooms with highly collaborative pairs working together result in positive perceptions amongst students and moreover fairness in grading, stronger class bonding, and higher degree of social support, as well as higher achievement scores and a strong learning outcome are its byproduct.

Investigations about class size have found how class size affects student and teacher behaviours. Most of the times, smaller classes are linked with students who are less anxious and are more frequently engaged rather than showing symptoms of behavioral problems that are usually found in big classrooms. It is all together different thing that teacher uses same instructions in both the classes whether it is small or a big one. In large classrooms, teachers spend more time to manage the students' behavioral issues, lack of assistance and too many students in the class are the main issues which are mostly brought forth that create havoc. Due to this, academic achievement is of low level.

Teacher child ratio is generally flawed and pays a crucial role in behavioral problems as size of class is big. It has been a common factor in all the researches that classroom with 40 or more students result in lesser engagement and dissemination of knowledge whereas a small class of 30 or less number of children shows more engagement and passing on of information that results in extended learning.

Enormous planning and careful thoughts are needed to enhance the environment. Many educators lay emphasis on the fact that classroom environment must be such that it keeps children engaged. It would help in motivating kids, enhance learning, and control behavioural issues that would have emanated in the absence of proper physical layout. Teachers need to focus on various ways in order to organize learning spaces for children who come from different backgrounds. In schools, it is mostly teachers who decide where students will sit.

Fernandes, Huang \& Rinaldo (2011) say it would be good for students if the learning activity dictated the seating. On the topic of giving a free choice of seats, they point out the learning experience for students is different for those at the front than for those nearer the back of the room. And, throwing it open to students to decide means some will get a better pick than others. 'Students who enter the classroom first may be in the position to select desirable seats first; thus, those who are unable to come first may be left with seats they do not desire.'

A recent study in the Netherlands explored not only the different types of seating arrangements in elementary schools, but also the teachers' considerations for deciding who sits where 
(Gremmen, van den Berg, Segers, \& Cillessen, 2016).

\section{The Psychological Environment:}

In a classroom a psychological environment is also created, based on the interaction in the classroom with students and teachers. Studies have been particularly directed on students' class participation rates, teachers support, and communication of learning objectives.

Many teachers connect student engagement and behaviour during work with classroom participation. The idea of feeling supported as students have also been widely examined in the classroom environment literature. When students feel that they receive emotional support and encouragement from their teachers and academic support from their classmates they are more likely to be engaged in the classroom and will be self disciplined.

Some students and teachers are more focused on getting grades than on gaining of objectives; these students and teachers are believed to be performance oriented rather than skill oriented. Researchers have found that whereas students who are more focused on grades are likely to have higher grades, whereas those students who are more focused on mastering objectives are likely to absorb themselves in more academically challenging work that will enhance their learning and will assimilate information for a longer period of time.

By far the most vital variable is how a teacher relates to the pupils in his or her class. The main endeavor ought to be to create an emotionally safe space without relinquishing the role as the teacher. This needs right amount of balance that keeps teacher and taught secure. Students need to know that the teacher is in charge of the classroom and of their relationship at the time the teacher must be truly a concerned person who is ever ready to extend a helping hand in order to deal with problems that are faced by many adolescents.

\section{Teacher's Role in the Classroom Environment:}

Classroom managers play an important role to determine teaching success. Great teachers are effective with students of all their learning outcomes in their classes. Effective teachers are those who use specific techniques to improve their teaching. Even if the school they work is not providing enough support, individual teacher can produce a strong gains in learning environment.
The research studies suggested teachers include classroom management plans and make a strong bonding with their students. Classroom rules and procedures should be introduced early in the school year and consequences should be enforced on regular basis across students and throughout the school year. Research has shown that regular and impartial behaviour of teachers have a positive effect on behaviour of students as well as in their academic outcome. It has been found that teachers who run respectful classrooms are in turn more respected by their students, and students believe that these teachers also hold higher learning expectations. A very important role of the teacher is to monitor students' performances and maintains records such as lessons plan, attendance, assessments and to maintain written stock of students' development. With all this information, the teacher will find it way easier to get to know the students properly and adopt different strategies that will surely ensure successful learning.

\section{Encouraging Student Success:}

Get to know the child. Solicit support from family members. Discover the child's likes and dislikes. Never humiliate a child in front of others. You can't imagine how this can negatively impact the child. Shouting at children all day is ineffective. Talk to children in a polite way so they can also learn good talking behaviour. Share your experiences with your students. Students want to know that you are human too. Acknowledge good behavior of your students. Give your students choices. Repeated choice opportunities allow students to build a feeling of ability to do something in a great way and avoid challenging behaviours. Help students celebrate their successes, however small. This will help them for self motivation; explore positive thoughts and actions about themselves.

Teachers can help students achieve their goal by helping the students feel like an important part of the school, creating learning environment that reinforce the view that students can do their best in academics, seeking out, praising any effort of students make toward the learning process, encouraging students to ask questions when they do not understand something.

\section{Teacher-Student Relationships:}

It is important to communicate with students in an appropriate way. It is also important that teachers are interested in the progress and learning of the students and individuals and the class as a whole. Students with good relationship with the teachers easily accept the rules and procedures and the disciplinary actions 
taken by their teachers. Teachers should be effective instructors and lecturers, as well as friendly and helpful. Teachers should be able to empathize with students, understand their problems and work upon them and listen to them. The nature of an effective teacher-student relationship is one that addresses the needs of different types of students. Consistent communication is the most important part as it creates strong bonding between the teacher and the student. The more the teacher communicates well, the higher is the chance of fast and effective learning at the student's end. A positive and good teacher student relationship helps students feel more comfortable and safer in the classroom. A positive teacher student relation has a positive impact on classroom management and affects learning and growth of the students. A good relation between teacher and student is very important for the development of the student's self esteem and enhancing their enthusiasm and success.

\section{Classroom Rules:}

Two most important aspects of classroom management are as follows:

1. Rules and procedures

2. Disciplinary actions

Effective classroom management needs good rules. Rules and procedures vary from one teacher to another and from one classroom to another; it is good if class teacher makes the classroom rules. They should be flexible and a teacher can make changes according to the need of the class. The most effective classroom management involves the design and implementation of classroom rules. Rules should not be passed on in a mandatory way to the student community. The proper design of rules involves explanation and group input. Explanation is important in helping the students to see the need for the rule before they accept it.

\section{Some Classroom Rules are as follows:}

1. Be on time

2. Be respectful to classmates, teachers and school property

3. Listen to the teacher and classmates

4. Follow the directions given by teacher

5. Obey all school rules

6. Be kind

7. Switch off lights, fans and AC before leaving the class

8. Raise your hand when you would like to speak in class
9. Arrange furniture properly

10. Throw garbage into the dustbin

11. No talking when the teacher is talking

12. All assignments must be done on time

13. Do not shout in the class

14. Don't use foul language

15. Treat others with kindness and respect

Teachers can frame classroom rules according to the need of their class and also involve students.

\section{Designing Rules and Regulations and Students' involvement in the same:}

Students who differ in interests, personality and level of thinking can be seen in any class. In such a situation and proper running of the class, certain rules, regulations and procedures are made and have to be followed strictly.

As an educator, we have to apply certain classroom rules and procedures for witnessing change in behaviour of students. The most effective teachers don't just enforce rules and regulations upon students. On the contrary, they take help of students while designing rules and regulations. A healthy group discussion on a certain topic of significance will produce a better rule that all can follow amicably. The teacher, no doubt will have the final say in the matter after having healthy discussion with the class. Rules that are framed after mutual consensus with students are an important aspect of classroom management. It not only affects their behaviours but also play a major role in their academic graph.

If teachers involve students directly in the creation of rules it leaves less room for confusion. When students are direct part of the process, they comprehend everything better. Involving students in the process will make them understand the power of collaboration.

As the students get involved in making the rules, they are more likely to follow them. Students also will be able to use their critical thinking and problem solving skills as they develop ideas to share with others. It has a positive impact on students' behaviour when a teacher involves them in designing the classroom rules.

\section{Implications and Considerations:}

Classroom environment is surely a broad term and the past and ongoing research in this area has defined it in many different ways according to theory as well 
as in its practical form. Without going in the details, it can be easily acknowledged that there are many important findings from the research on the whole that can impact students' learning and behaviour with regard to classroom environment. At the same time, it cannot be denied that due to continuous changes in modern technology and cultural shifts, the term classroom environment is undergoing alteration.

One of these areas to consider is the environment beyond the classroom. Recently, there has been debate on the impact of whole school environment on classroom environment. With great importance put on school-wide performance in order to display school success in terms of annual academic progress of students, there is too much pressure on teachers to deliver high scores in board exams along with standardized tests. The same echoes also in the classroom and is communicated in different ways to students and it impacts their experiences in the classroom. There is research being done to examine the implications of the high-standardised testing for the psycho-social dimension of the classroom as well as how this approach has influenced instructional strategies used by educators in the classrooms.

In addition to this, the definition of classroom environment continues to progress with the development of varied online courses and growing use of technology in the classrooms. Classrooms are now highly networked places, taking the teaching beyond the physical walls, enabling students to interact via Skype, video conferencing, various apps and blogs. The addition of technology to the classroom has been game changer, and research has only begun to consider these new aspects and their overall impact on classroom outcomes.

There is no doubt that information accessed from ongoing studies of classroom environment reveal that it impacts teachers' knowledge. Learning about various features that may shape students' views of their learning environment, how teachers' actions appear to students, and how changes made to the learning environment may encourage learning continue to be of vital importance to teaching community.

\section{Conclusions}

An effective classroom management plan creates a good environment for learning and every student has opportunity to express him or herself without any hesitation and fear. Classroom management is a set of methods and skills used by the teachers to assists students in being more organized, thoughtful and disciplined.
In today's world, even after so many technological advancements, a good teacher cannot be replaced. When we talk about school, students are the main part and giving them a safe, supportive and comfortable learning environment is the main concern. If teacher has a good planning in advance and implement it in an effective manner then no doubt, real teaching would happen and classroom would be termed as an ideal one. In such a classroom, children would be free to express themselves effectively and concrete learning will take place. Classroom management is important to the success of the students. A combination of good classroom layout, effective preventive measures for behaviour problems and implementation of joyful and engaging curriculum as well as actively involving all students in learning activities ensures that students' learning needs are met. In my classroom management plan, the main concern to have the safe learning environment for the students.

\section{Reference:}

1. Bronfenbrenner, U. (1977). Toward ecology of human development. American Psychologist, 32, 513-531.

2. Patrick, H., Ryan, A., \& Kaplan, A. (2007). Early adolescents' perceptions of the classroom social environment, motivational beliefs, and engagement. Journal of Educational Psychology, 99, 83-98.

3. Froyen L.A. \& Iverson A.M. (1999) School wide and Classroom Management; The reflective educator leader (3rd ed.).Upper Saddle River NJ: Prentice Hall.

4. Byer, J. L. (1999). The effects of students' perceptions of social climate in middle school social studies classes on academic self-concept.

5. Bhattacharjee, S. \& Mahanty, N.S. (1999). Impact of new teaching-learning methodologies in classroom transaction. Assam, Morigaon: DIET.

6. Fernandes, A. C., Huang, J., \& Rinaldo, V. (2011). Does where a student sits really matter? The impact of seating locations on student classroom learning. International Journal 